\title{
Quality-of-life evaluation in patients with laryngotracheal diseases
}

\author{
Benoit Jacques Bibas, Paulo Francisco Guerreiro Cardoso, Helio Minamoto, \\ Paulo Manoel Pêgo-Fernandes
}

\begin{abstract}
Division of Thoracic Surgery, Heart Institute (InCor), Hospital das Clinicas da Faculdade de Medicina da Universidade de São Paulo, São Paulo, Brazil

Correspondence to: Benoit Jacques Bibas, MD. Instituto do Coração, Rua Dr. Enéas de Carvalho Aguiar 44, bloco 2, 7o andar, Secretaria de Cirurgia Torácica, Cerqueira Cezar, São Paulo, SP 05403-000, Brazil. Email: benoitbibas@hotmail.com.
\end{abstract}

Submitted Jan 30, 2020. Accepted for publication Feb 21, 2020.

doi: $10.21037 /$ tcr.2020.02.60

View this article at: http://dx.doi.org/10.21037/tcr.2020.02.60

\section{Introduction}

Health-related quality of life (HRQL) is a brad concept, but in general terms depicts the self-reported physical and mental condition of an individual. This is a consequence not only of the disease, but also of the environmental conditions that surrounds the life of the patient (1). HRQL instruments are a fundamental part of patient-reported outcomes measures (PROMs). This type of analysis has gained widespread attention, and is a quintessential component of modern outcome assessment (2).

Benign laryngo, or laryngo-tracheal stenosis (LTS) may be defined in several manners. Still, there must be some degree of airway stricture at the level of the glottis, subglottis, or trachea (3). It is not merely an anatomical structural deformity that can be defined by its extension, diameter, and distance from the closest anatomic landmark, such as the vocal folds or the tracheal carina. LTS is a complex condition in its etiology, natural history, and clinical outcome. It may derive from various clinical entities, such as iatrogenic airway injuries (i.e., postintubation, posttracheostomy), autoimmune diseases (i.e., Granulomatosis with polyangiitis, relapsing polychondritis, sarcoidosis, amyloidosis), congenital, primary and secondary neoplastic diseases, and idiopathic $(4,5)$.

As consequence, patients usually experience dyspnea, stridor dysphonia, dysphagia, and in severe cases, phonation ablation (1,4-8). Furthermore, many patients will have a tracheostomy placed during an exacerbation event. At our institution, approximately $80 \%$ of the patients referred to us have an indwelling tracheostomy (4-8). This is known to have a severe negative impact in self-esteem and a substantial decrease in the overall quality-of-life perception
$(9,10)$. In our clinical practice, patients exhibit difficulties in daily tasks, such as talking on the phone or having a simple conversation, and are reluctant to engage in social activities. Furthermore, patient's ability to retain and acquire jobs are also deeply, ultimately causing social and financial problems to themselves and their caretakers.

Several groups have used specific health-related questionnaires to analyze patients with LTS. Most of them have studied the overall HRQL, but voice and dyspnea are also subject of attention.

\section{Overall HRQL}

Our group (1) prospective evaluated adult patients with benign tracheal or LTS treated with Montgomery T-tubes, Dumon silicone stents or tracheostomy. HRQL was evaluated using the SF 36 Health Survey. The SF-36 normbased results for the entire cohort were compared with random standardized control population. Of all 8 domains studied, only one (Vitality) actually scored in the mean of the control population. All other domains (physical Function and mental) were poorly scored and were placed 1 standard deviation below the mean, or 2 standard deviations below the mean. Both summaries, physical and mental, were 1 standard deviation below the mean. The conclusion of our study was that patients with tracheal stenosis have a poor quality-of-life. This impairment is noticeable in physical activities, as expected, but also in the mental state of the individuals.

The severity of the stenosis seems to correlate well with the worsening HRQL. Naunheim et al. (2) analyzed patients with idiopathic stenosis and correlated the severity of the 
disease with pulmonary function tests and four different HRQL scores (EQ-5D; RAND 36-Item Health Survey; Clinical COPD Questionnaire; and the Airway, Dyspnea, Voice, and Swallowing Summary Assessment). The study demonstrated through univariate analysis demonstrated that the four instruments had a significant correlation with the lung function tests, either as an aggregate score (ED-5D and CCQ) or along several domain scores (RAND-36 and ADVS).

This impairment seems to be reduced when the tracheal stenosis is surgically corrected. Wray et al. (11) evaluated 42 children with long-segment LTS submitted to slide tracheoplasty. HRQL was evaluated with a generic questionnaire (PedsQL4.0) after surgical reconstruction of the airway, and scores did not differ from healthy controls. Another study (3) indicated that over a 5-year time horizon, open reconstruction (cricotracheal/tracheal resection) had a higher cost but greater quality-adjusted life year, which resulted in a cost-effective result at the predetermined willingness-to-pay threshold. As compared with endoscopic dilations, open reconstruction had an incremental costeffectiveness ratio of U\$896 per quality-adjusted life year. When extended to a 10 -year time horizon, open reconstruction had a lower cost and produced a greater quality-adjusted life year, thus dominating the alternative of endoscopic dilation.

\section{Voice-related quality of life}

Since many patients with tracheal stenosis have dysphonia, and sometimes complete phonation ablation, the impact of the voice quality in the overall quality of life has been subject of investigation. Several groups have addressed this issue and tried to quantify the impact of the voice in the overall perception of the individual. Hillel and colleagues (12) conducted a retrospective review of patients who underwent balloon dilation for LTS. Preoperative and postoperative voice outcomes were analyzed before and after the procedure with a specific questionnaire (V-RQOL). This questionnaire is a validated disease-specific quality-oflife instrument that allows patients to rate their own selfperceived voice quality. Endoscopic dilation improved voice from a mean of 70.4 to 80.0 postoperatively $(\mathrm{P}=0.025)$. The same group (13) later on evaluated a small group of 13 patients with LTS treated with Montgomery T-Tubes. The primary outcome was to measure voice outcomes using V-RQOL scores in patients before and after Montgomery T-tube placement. The average calculated V-RQOL score between initial scores and those post-operatively was 43.5 to $79(\mathrm{P}<0.05)$, with improvement in the post $\mathrm{T}$-tube score compared to the pre-placement score. Furthermore, 5 patients $(38 \%)$ went from aphonia to voicing. As a downside, two patients had a worse calculated V-RQOL following T-tube placement.

Fiorelli et al. (14) performed a similar study, but in patients with tracheomalacia. Eleven individuals were evaluated and V-RQOL scores measured pre and post Montgomery silicone T-Tube placement. Stent placement resulted in significant improvement in social/emotional $(39.2 \pm 6.1$ vs. $66.8 \pm 1.9 ; \mathrm{P}=0.0001)$; physical functioning $(21 \pm 5.7$ vs. $56.4 \pm 5.3 ; \mathrm{P}=0.0001)$ and total $\mathrm{V}$-RQOL scores (33.9 95.4 vs. $61.3 \pm 6.1 ; \mathrm{P}=0.0001)$ after T-tube insertion, with a very low complication rate. This confirms that T-Tube placement is safe, can provide good phonation, and should be attempted whenever possible, even when definitive tracheal reconstruction is not amenable.

\section{Dyspnea-related quality of life}

One recent case series (15) included 14 patients that were evaluated with the V-RQOL, Dyspnea Index, and Clinical COPD Questionnaire, before and after endoscopic surgery. There was significant difference in dyspnea after endoscopic surgery, as demonstrated by both indexes. Dyspnea Index $(n=14)$ decreased from 26.9 to 6.6 (mean of difference, -20.3; 95\% CI, -27.9 to -12.7); COPD Questionnaire score decreased from 3.2 to 1.0 (mean of difference, $-2.2 ; 95 \%$ CI, -3.4 to -0.9 ). Furthermore, an increase in pulmonary function was also observed. Postoperative mean vital capacity increased from 2.5 to $3.1 \mathrm{~L}$ (mean of difference, $0.6 \mathrm{~L} ; 95 \% \mathrm{CI}, 0.3$ to $1.0 \mathrm{~L}$ ), whereas mean laryngeal resistance $(\mathrm{n}=14)$ decreased from 73.9 to $46.4 \mathrm{cmH}_{2} \mathrm{O} / \mathrm{L} / \mathrm{s}$ (mean of difference, $-27.5 \mathrm{cmH}_{2} \mathrm{O} / \mathrm{L} / \mathrm{s} ; 95 \% \mathrm{CI},-44.8$ to $-10.3 \mathrm{cmH}_{2} \mathrm{O} / \mathrm{L} / \mathrm{s}$ ) postoperatively.

\section{Conclusions}

Tracheal stenosis is a devastating condition that imposes impairments in respiratory, voice and overall quality-of-life. There is sufficient evidence through HRQL questionnaires that these patients experience poor self-esteem and a substantial decrease in the overall quality-of-life perception. Surgical airway reconstruction and endoscopic dilatational procedures appear to minimize those issues, by improvement of voice, breathing and physical status, and should be encouraged. 


\section{Acknowledgments}

Funding: None.

\section{Footnote}

Provenance and Peer Review: This article was commissioned by the editorial office, Translational Cancer Research for the series "Recent Developments in Benign Tracheal Stenosis". The article did not undergo external peer review.

Conflicts of Interest: All authors have completed the ICMJE uniform disclosure form (available at http:// dx.doi.org/10.21037/tcr.2020.02.60). The series "Recent Developments in Benign Tracheal Stenosis" was commissioned by the editorial office without any funding or sponsorship. BJB and PFGC served as the unpaid Guest Editors of the series. The authors have no other conflicts of interest to declare.

Ethical Statement: The authors are accountable for all aspects of the work in ensuring that questions related to the accuracy or integrity of any part of the work are appropriately investigated and resolved.

Open Access Statement: This is an Open Access article distributed in accordance with the Creative Commons Attribution-NonCommercial-NoDerivs 4.0 International License (CC BY-NC-ND 4.0), which permits the noncommercial replication and distribution of the article with the strict proviso that no changes or edits are made and the original work is properly cited (including links to both the formal publication through the relevant DOI and the license). See: https://creativecommons.org/licenses/by-nc-nd/4.0/.

\section{References}

1. Bibas BJ, Cardoso PFG, Salati M, et al. Health-related quality of life evaluation in patients with non-surgical benign tracheal stenosis. J Thorac Dis 2018;10:4782-8.

2. Naunheim MR, Paddle PM, Husain I, et al. Quality-ofLife Metrics Correlate With Disease Severity in Idiopathic Subglottic Stenosis. Laryngoscope 2018. [Epub ahead of print].

3. Yin LX, Padula WV, Gadkaree S, et al. Health Care Costs and Cost-effectiveness in Laryngotracheal Stenosis. Otolaryngol Head Neck Surg 2019;160:679-86.
4. Cardoso PFG, Bibas BJ, Minamoto H, et al. Prophylaxis and Treatment of Complications After Tracheal Resection. Thorac Surg Clin 2018;28:227-41.

5. Bibas BJ, Terra RM, Oliveira Junior AL, et al. Predictors for postoperative complications after tracheal resection. Ann Thorac Surg 2014;98:277-82.

6. Bibas BJ, Guerreiro Cardoso PF, et al. Surgical Management of Benign Acquired Tracheoesophageal Fistulas: A Ten-Year Experience. Ann Thorac Surg 2016;102:1081-7.

7. Bibas BJ, Cardoso PFG, Minamoto H, et al Surgery for intrathoracic tracheoesophageal and bronchoesophageal fistula. Ann Transl Med 2018;6:210.

8. Bianchi ET, Guerreiro Cardoso PF, et al; Surgery of the Digestive Tract Group. Impact of fundoplication for gastroesophageal reflux in the outcome of benign tracheal stenosis. J Thorac Cardiovasc Surg 2019;158:1698-706.

9. Gilony D, Gilboa D, Blumstein T, et al. Effects of tracheostomy on well-being and body-image perceptions. Otolaryngol Head Neck Surg 2005;133:366-71.

10. Hashmi NK, Ransom E, Nardone H, et al. Quality of life and self-image in patients undergoing tracheostomy. Laryngoscope 2010;120 Suppl 4:S196.

11. Wray J, Ryde M, Butler CR, et al. Quality of life can be good after slide tracheoplasty for long-segment tracheal stenosis. Interact CardioVasc Thorac Surg 2019;29:876-82.

12. Hillel AT, Karatayli-Ozgursoy S, Benke JR, et al. Voice quality in laryngotracheal stenosis: impact of dilation and level of stenosis. Ann Otol Rhinol Laryngol 2015;124:413-8.

13. Dhillon VK, Akst LM, Best SR, et al. Voice Outcomes in Laryngotracheal Stenosis: Impact of the Montgomery T-tube. Clin Surg 2018;3:1855.

14. Fiorelli A, Natale G, Freda C et al. Montgomery T-tube for management of tracheomalacia: Impact on voicerelated quality of life. Clin Respir J 2020;14:40-6.

15. Samad I, Akst L, Karatayli-Özgürsoy S, et al. Evaluation of Dyspnea Outcomes After Endoscopic Airway Surgery for Laryngotracheal Stenosis. JAMA Otolaryngol Head Neck Surg 2016;142:1075-81.

Cite this article as: Bibas $\mathrm{BJ}$, Cardoso PFG, Minamoto $\mathrm{H}$, Pêgo-Fernandes PM. Quality-of-life evaluation in patients with laryngotracheal diseases. Transl Cancer Res 2020;9(3):20992101. doi: $10.21037 /$ tcr.2020.02.60 